\title{
„RUGĂCIUNEA DE FOC” A SFÂNTULUI IOAN CASIAN ȘI MIȘCAREA RUGULUI APRINS: PREMISE PENTRU UN „ISIHASM LAIC"
}

\section{Cosmin Ionel MAFTEI*}

\begin{abstract}
The Prayer of fire” of Saint John Cassian and the movement of The Burning Bush: starting point for a „secular hesychasm". The image of the burning bush from The Book of Exodus chapter 3 has been interpreted by The Holy Fathers in a Christological way, as an image of Incarnation from Virgin Mary, but as well as an image of hesychast prayer. On this regard, Saint John Cassian reminds of the 'prayer of fire' as the highest level of prayer, known by few but which proves to be the result of an hesychast tradition of the Egyptian desert, of the fourth century. This is why there are images of the prayer of fire presented in the Paterikon, at different fathers and in some stories without being named as prayer of fire. These passages are similar to the description made by Saint John Cassian. Developed by the Fathers of the $14^{\text {th }}$ century, the hesychast prayer becomes the centre of the clerical/spiritual life for the entire Eastern Christianity. The hesychast prayer has spread in the majority of the orthodox countries after the appearance of Philokalia (1782). In our country, the hesychasm appeared early through the writings of Saint Basil from The Glade of the Apple (Poiana Mărului) and Saint Paisie from Neamț (XVIIIth century) and later through the translation of Philokalia by priest Dumitru Stăniloae, beginning with the year of 1946. Along this, an important part to the spread of hesychasm on the Romanian territory, was played by The Movement of the Burning Bush (1945-1948), which started at The Antim Monastery and trained in the art of orthodox spirituality the intellectuals of Bucharest and others. The urge addressed by Saint Apostle Paul to
\end{abstract}

"Priest, PhD Student, Faculty of Orthodox Teology at „1 Decembrie 1918” University, Alba Iulia, Romania.

${ }^{1}$ Realizat sub îndrumarea ÎPS Prof. Univ. Dr. Irineu Pop, Universitatea „1 Decembrie 1918” din Alba Iulia, care şi-a exprimat acordul pentru publicare. 
Thessalonians: „Pray constantly” (I Thessalonians 5, 17), and also the calling to holiness addressed to all people (Mathew 5, 48), the secular hesychast model exemplified by Saint Nicolas Cabasilas, ruler Neagoe Basarab, „the Russian pilgrim” and the Movement of the Burning Bush, represent enough proof for the existence of a secular hesychasm. Starting from these confessions we consider being of imperative importance that the spiritual revival of the actual society to begin with the „Prayer of Christ".

Keywords: prayer, hesychasm, Philokalia, communion, society, mission.

\section{Introducere}

Îndemnul Mântuitorului nostru Iisus Hristos de a ajunge la desăvârşire este adresat fiecărui om, lucru înţeles și de Sfinții Apostoli care îndeamnă și ei comunitățile creștine la desăvârșire prin practicarea virtuțiilor și prin rugăciune neîncetată. Modelul primilor creștini care stăruiau în rugăciune s-a perpetuat peste veacuri și a prins rădăcini adânci în cadrul monahismului egiptean unde rugăciunea monologistă a avut accente puternice ce au dus mai târziu la rugăciunea isihastă specifică Răsăritului creștin.

În cele ce urmează vom încerca să mergem pe firul Tradiției pentru a identifica importanța, necesitatea și obligativitatea fiecărui creștin de a se ruga folosindu-se de „Rugăciunea lui Iisus”, precum și identificarea unui ,isihasm laic” pe teritoriul țării noastre.

\section{1. „Rugăciunea de foc”}

Imaginea rugului aprins din cartea Ieșirea, capitolul 3, a fost interpretată de către Sfinții Părinți în sens hristologic, ca imagine a Intrupării din Fecioara Maria dar și ca imagine a rugăciunii isihaste, a rugăciunii neîncetate. În acest sens, Sfântul Ioan Casian (360-435) amintește de „rugăciunea de foc"”2 ca despre cel mai înalt fel de rugăciune,

${ }^{2}$ Monique Alexandre, „La priere de feu chez Jean Cassien”, în Cristian BadiLita et Attila JАKAB (ed.), Jean Cassien entre l"Orient et l"Occident. Actes du colloque internationel organise par le New Europe College en collaboration avec la Ludwing Boltzmann Gesellschaft (Bucarest, 27-28 septembre 2001), Paris: Beauchesne Editeur, Iaşi: Edit. Polirom, 2003, p.169-203. 
cunoscută de foarte puțini dar care se dovedește a fi rezultatul unei tradiții isihaste a pustiului egiptean din secolul al IV-lea.

Descriind această rugăciune de foc a fi cea mai înaltă formă de rugăciune, Sfântul Ioan Casian arată că ea e cunoscută şi practicată de foarte puţini, fiind de neexprimat prin cuvinte, în acest sens spune:

„Această rugăciune, mai presus de orice simţire omenească, nu se poate arăta prin nici un sunet al vocii, prin nici o mişcare a limbii şi prin nici o rostire de cuvinte, ci numai mintea luminată de strălucirile cereşti o spune nu prin vorbe înguste şi omeneşti, ci prin toate simţirile. Ca dintrun izvor foarte bogat o revarsă cu îmbelşugare şi o aruncă în chip minunat spre Dumnezeu, grăind atâtea în acel foarte scurt moment al timpului câte mintea nu poate rosti uşor şi nici străbate, când se întoarce în sine însăşi. Această stare ne-a arătat-o şi Domnul nostru prin forma acelor rugăciuni pe care, cum este scris, El le-a revărsat, când s-a urcat pe munte, sau când, în agonie, a vărsat chiar picături de sânge, rugându-Se în tăcere, ca sublim exemplu de rugăciune, pe care numai El îl putea da"’3.

\section{De la „Rugăciunea de foc” din pustia egipteană la rugăciunea isihastă a secolului al XIV-lea}

Experiența acestei rugăciuni se pare a o fi avut și psalmistul David când zice: „Înfierbântatu-s-a inima mea înăuntrul meu şi în cugetul meu se va aprinde foc" (Psalm 38, 4), înfierbântare care se datorează rugăciunii, căci mărturisește: „Cu toată inima Te-am căutat pe Tine; În inima mea am ascuns cuvintele Tale" (Psalm118;10-11). Imaginea acestei rugăciuni de foc se regăsește și în Pateric la diferiţi părinți și în unele relatări care se potrivesc descrierii făcute de Sfântul Ioan Casian.

În acest sens se spunea despre avva Pamvo, că precum a luat Moise icoana slavei lui Adam, când s-a slăvit faţa lui, aşa şi faţa avvei Pamvo, strălucea ca fulgerul şi era ca un împărat şezând pe tron. La fel erau şi avva Silvan şi avva Moise ${ }^{4}$. O și mai clară descriere a rugăciunii de foc o

3 Sfântul IOAN CASIAN, Convorbirea $I X, X X V$, în Sfântul IOAN CASIAN, Convorbiri duhovnicești, traducere din limba latină David Popescu, București, Edit. Institutului Biblic și de Misiune al Bisericii Ortodoxe Române, 2004, p. 237- 238.

${ }^{4}$ Avva Pamvo (12), în Patericul sau apoftegmele părinților din Pustiu, colecția alfabetică, text integral, traducere, introducere, prezentări și postfață de Cristian Bădiliță, București, Edit. Adevărul Holding, 2011, p. 304. 
aflăm la avva Arsenie despre care se spune că în timpul rugăciunii era pe de-a-ntregul ca focul ${ }^{5}$.

Altă relatare despre rugăciunea de foc o găsim la avva Iosif din Panefo unde se spune că a venit avva Lot la avva Iosif şi i-a spus: Avvo, îmi fac mica mea rugăciune după puterile mele şi micul meu post, şi rugile şi meditaţia şi reculegerea, şi după puterile mele îmi curăţesc gândurile. Ce să mai fac? Bătrânul se ridică, întinzându-şi mâinile spre cer, şi i s-au făcut degetele ca zece flăcări. Şi îi spuse: Dacă vrei, fă-te foc, cu totul ${ }^{6}$. Idee regăsită și la Amma Singlitichia care spunea că ,aşa trebuie şi noi să aprindem în noi înşine focul dumnezeiesc, cu lacrimi şi trudă"7.

La avva Macarie Egipteanul găsim o frumoasă descriere a rugăciunii de foc atunci când vorbește despre cei doi frați veniți în pustie pentru a deveni monahi și pe care-i vizitează după trei ani de zile pentru a le vedea trăirea moment în care Dumnezeu îi descoperă lucrarea lor, anume faptul că în timpul rugăciunii din noapte acoperișul chiliei s-a deschis şi s-a făcut lumină ca ziua, dar ei nu vedeau lumina. Mai mult de atât, atunci când se rugau flăcări de foc ieșeau din gura lor și ajungeau până la cer ${ }^{8}$.

$\mathrm{Cu}$ mare probabilitate această „rugăciune de foc” specifică monahismului egiptean al secolului IV reprezintă rugăciunea isihastă caracteristică secolului XIV după cum putem vedea din similitudinile dintre relatările Sfântul Ioan Casian și Sfântul Grigorie Palama (12961359), reprezentantul de seamă al isihasmului. În acest sens sunt comune următoarele idei: rugăciunea neîncetată $\breve{ }^{9}$, scurtă ${ }^{10}$ și monologică ${ }^{11}$; lumina

${ }^{5}$ Avva Arsenie (27), în Patericul sau apoftegmele părinților din Pustiu,, p. 59.

${ }^{6}$ Avva Iosif din Panefo 7, în Patericul sau apoftegmele părinţilor din Pustiu, p. 181-182.

${ }^{7}$ Amma Singlitichia (1), în Patericul sau apoftegmele părinților din Pustiu, p. 349.

${ }^{8}$ Avva MACARIE Egipteanul (33), în Patericul sau apoftegmele părinților din Pustiu, p. 223-225.

9 Sfântul IOAN CASIAN, Convorbirea $X, X, 13-15$, în Sfântul IOAN CASIAN, Convorbiri duhovnicești, p. 261.

${ }^{10}$ Idem, Convorbirea IX, XXXVI, 1, în Sfântul IOAN CASIAn, Convorbiri duhovnicești, p. 247.

${ }^{11}$ Columba Stewart, Cassian monahul. Învățătura ascetico-mistică, trad. Ioan I. Ică jr. și Cristian Pop, Sibiu, Edit. Deisis, 2000, p. 171-172; John MeYENDORFF, $O$ introducere în studiul vieții și operei Sfântului Grigorie Palama, traducere din limba franceză de Măriuca și Adrian Alexandrescu, studiu introductiv și traducere din limba greacă de Marius Portaru, București, Edit. Nemira, 2014, p. 295-296. 
ca mijloc și obiect al viziunii ${ }^{12}$, precum și accentul pus pe Schimbarea la Față a Domnului pe muntele Tabor ca mărturie eshatologică a împărtășirii de lumina necreată ${ }^{13}$.

Rugăciunea isihastă propovăduită de către Sfântul Grigorie Palama nu viza doar pe monahi ci cu precădere pe mireni, lui datorându-se scoaterea isihasmului din pustie și răspândirea lui în lume printre laici ${ }^{14}$. Un important „,isihast laic" al epocii fiind Sfântul Nicolae Cabasila (1322-1392), care a încercat să demonstreze, atât practic, cât și teoretic printr-o spiritualitate centrată liturgic și sacramental, că ,viața în Hristos” poate fi trăită și de creștinii din lume, nu doar de monahi, învățând un isihasm în sens $\operatorname{larg}^{15}$.

\section{3. „Isihasmul laic" în spațiul carpato-danubiano-pontic}

Dezvoltată de Părinții secolului al XIV-lea, rugăciunea isihastă devine centrul vieții duhovnicești pentru întreg Răsăritul creștin răspândindu-se după apariția Filocaliei (1782) în majoritatea țărilor ortodoxe. Totuși, prima mărturie a existenței ,isihasmului laic" pe teritoriul țării noastre o găsim la Sfântul Voievod Neagoe Basarab (1459-1521) care în lucrarea sa „Învățăturile lui Neagoe Basarab către fiul său Teodosie”, lucrare ce reprezintă primul moment al literaturii române, rezumă viața creștinortodoxă la comportamentul exemplar al domnitorului și al slujitorilor săi, care ar trebui să fie al oricărui creștin, comportament caracterizat de rugăciunea permanentă care trebuie să însoțească orice lucrare ${ }^{16}$.

12 Sfântul IOAN CASIAN, Despre Intruparea Domnului, contra lui Nestorie, III, VI, 3, în Sfântul IOAN CASIAN, Scrieri alese. Așezămintele mânăstirești și convorbiri duhovnicești, trad. Vasile Cojocaru și David Popescu, studiu introductiv și note de Nicolae Chițescu, în col. PSB, vol. 57, București, Edit. Institutului Biblic și de Misiune al Bisericii Ortodoxe Române, 1990, p.792; John MEYENDORFF, O introducere în studiul vieții și operei Sfântului Grigorie Palama, p. 344-346.

13 Sfântul IOAN CASIAN, Convorbirea X, VI, în Sfântul IOAN CASIAN, Convorbiri duhovnicești, p. 253-254; John MEYENDORFF, O introducere în studiul vieții și operei Sfântului Grigorie Palama, p. 375-377.

14 Vasile ANDRU, Isihasmul sau meșteșugul liniștirii, București, Edit. Herald, 2010, p. 140-141.

15 Ioan I. ICĂ JR., „Nicolae Cabasila - viața uitată a unui intelectual umanist isihast”, în vol. Teologie ortodoxă în destin românesc: omagiu Părintelui Profesor Ilie Moldovan la 80 de ani, Sibiu, Edit. Andreiana, 2008, p. 380.

16 Alexandru Surdu, ,'Isihasmul laic" la Neagoe Basarab”, în Omagiu Părintelui Academician Dumitru Popescu, Alba Iulia, Edit. Reîntregirea, 2005, p. 52. 
O altă mărturie despre ,isihasmul laic” o găsim la Sfântul Vasile de la Poiana Mărului (1692-1767), părintele duhovnicesc și povățuitorul Sfântului Paisie Velicikovski (1722-1794), care în scrierile sale despre rugaciunea lui Iisus îndeamnă pe toți, arhierei, preoți, călugări și mireni, să practice isihasmul ${ }^{17}$.

Cel care v-a introduce spiritualitatea și rugăciunea isihastă în viața de obște și care v-a traduce Filocalia în limba slavonă (1793) v-a fi Sfântul Paisie de la Neamț (Velicikovski), primul care accentuează interdependența dintre Scriptură, Filocalie și rugăciunea lui Iisus ${ }^{18}$. În mișcarea sa isihastă de revigorare spirituală au fost incluşi și mirenii, cărora le recomanda practicarea „Rugăciunii lui Iisus”19.

\section{4. „Isihasmul laic” în secolul XX: Traducerea Filocaliei în limba română și Mișcarea Rugului Aprins}

Pentru teologia ortodoxă modernă Filocalia are o importanță majoră, reprezentând un punct de reper al vieții duhovnicești, încât publicarea ei la Veneția în anul 1782 de către Sfântul Nicodim Aghioritul și în Moldova și Rusia de către Sfântul Paisie de la Neamț a însemnat declanșarea mișcării neoisihaste specifică secolului XVIII, iar prin traducerea ei în secolul XX în limbile moderne s-a creionat mișcarea neopatristică ortodoxă $\breve{a}^{20}$. Pentru teologia ortodoxă românească reprezentativ pentru această mișcare neopatristică este Părintele Dumitru Stăniloae care începând cu anul 1946 traduce şi editează Filocalia în limba română devenind „,o voce modernă a Părinților”21.

Concomitent cu traducerea Filocaliei în limba română ia naștere Mișcarea Rugului Aprins de la mănăstirea Antim (1945-1948) care a

${ }^{17}$ FILOCALIA, volumul VIII, traducere din grecește, introducere și note Dumitru Stăniloae, București, Edit. Humanitas, 2009, p. 517.

18 Elia CitTERIO, „Un stareț și autobiografia lui”, în Cuviosul Paisie de la Neamț Velicikovski, Autobiografia și Viețile unui stareț urmate de Așezăminte și alte texte, ediția a III-a adăugită, studiu introductiv de Elia Citterio, ediție îngrijită de Ioan I. Ică jr., Sibiu, Edit. Deisis, 2015, p. 16, 30.

${ }^{19}$ Vasile ANDRU, Isihasmul sau meșteşugul liniștirii, p. 158-159.

${ }^{20}$ Ciprian Iulian TOROCZKAI, Tradiția patristică în modernitate: ecleziologia pr. Georges V. Florovsky (1893-1979) în contextul mişcării neopatristice contemporane, Sibiu, Edit. Andreiana, 2008, p. 29-32.

${ }^{21}$ Ibidem, p. 75-77. 
antrenat în tainele spiritualităţii ortodoxe elita intelectuală a Bucureștiului şi nu numai. Întemeierea Rugului Aprins, sau după cum spune Mitropolitul Antonie Plămădeală momentul pregătitor, a constat în întâlnirea fondatoare din cadrul simpozionul de la Cernăuți din 1-7 august 1943 a cărui program a fost unul isihast sub egida Schimbării la Față ${ }^{22}$.

Iniţiatorul „Rugului Aprins” a fost Sandu Tudor, un laic, poet și scriitor, mai târziu devenit Părintele Daniil de la Rarău, care în urma vizitării Sfântului Munte experiază lucrarea Rugăciunii lui Iisus și revenit în țară dă naștere mișcării duhovnicești isihaste ${ }^{23}$ care antrenează clerici, călugări și în special laici, intelectuali. Dintre participanții de la Cernăuți amintim pe: Pr. Nicolae M. Popescu, Alexandru Elian, Alexandru Mironescu, Anton Dumitriu, Paul Sterian, Constantin Noica, Petru Manoliu, Arhim. Benedict Ghiuș și Sandu Tudor.

După anul 1945 Mișcarea Rugului Aprins ia ființă în București continuând programul isihast de la Cernăuți la Mănăstirea Antim unde numărul participanților crește, în special al laicilor ${ }^{24}$. Dacă din punct de vedere istoric Mișcarea Rugului Aprins reprezintă un fenomen de atitudine, de rezistență spirituală ortodoxă împotriva comunismului, din punct de vedere spiritual reprezintă ,,al treilea moment de seamă al istoriei spiritualității românești” după momentul paisian de la Mănăstirea Neamț şi cel al Sfântului Calinic de la Cernica ${ }^{25}$.

În acest sens Roman Braga spunea că ,,pentru grupul de la Antim isihasmul era metoda de vindecare a nebuniei omului modern a cărui

${ }^{22}$ Carmen CiorneA, „Să nu fiți căldicei”. Sandu Tudor și întemeierea Rugului Aprins (1940-1952), prefață de Marius Oprea și cuvânt înainte de Nicolae Bordașiu, București, Edit. Eikon, 2018, p. 47-51; André SCRIMA, Timpul rugului aprins: maestrul spiritual în tradiția răsăriteană, prefață de Andrei Pleșu, București, Edit. Humanitas, 2010, p. 174-178; †Antonie PlĂMĂDEALĂ, Rugul Aprins, Sibiu, Tipografia Eparhială, 2002, p. 24-27.

${ }^{23}$ IOAN DE LA RARĂU, Rugul Aprins: Starețul Daniil de la Rarău, Ed. a II-a revizuită și completată, Vatra Dornei, Edit. Panaghia, 2017, p. 82.

${ }^{24}$ Amintim dintre ei pe: Vasile Alecsandri, Vasile Voiculescu, Tudor Vianu, Ion Barbu, Ion Marin Sadoveanu, Vladimir Streinu, Alexandru Elian, Mircea Vulcănescu, Pr. Dumitru Stăniloae, Sofian Boghiu, Petroniu Tănase, Andrei Scrima, Roman Braga, Adrian Făgețeanu, Nicolae Bordașiu, Leonida Plămădeală etc. - †Antonie Plămădeală, Rugul Aprins, p. 28-29; Carmen Ciornea, Chipul Rugului Aprins, București, Edit. Eikon, 2015, p. 248.

25 †Antonie Plămădeală, Rugul Aprins, p. 18, 19, 35. 
dramă este fuga de sine, fuga de o confruntare cu Dumnezeu și amețeala cu mirajul lucrurilor din afară" 26 , lucru confirmat și de Alexandru Mironescu în jurnalul său de după detenție ${ }^{27}$. Iar Sandu Tudor spunea că rugăciunea este principiul tuturor lucrurilor și că „rugăciunea cea adevărată înseamnă să arzi fără să te mistui, să arzi dumnezeiește, fără cenușă"28.

Chiar numele „Rugul Aprins” reprezintă o parte a Revelației, a aseității dumnezeiești (Ieșire 3, 14), fiind icoană a Întrupării și simbol al Maicii Domnului, a rugăciunii perfecte ${ }^{29}$. De altfel, chiar Sfântul Grigorie Palama vede în Fecioara Maria prototipul vieții isihaste ${ }^{30}$, ceea ce-l face pe teologul Boris Bobrinskoy să afirme că:

„Această temă a rugăciunii neîncetate în Maria a fost reluată în România de către un grup de practicanți, „Rugul Aprins”, ivit din și moștenitor al marii tradiții filocalice de la Optina. Unul dintre fructele meditației comune a acestui grup a fost compunerea unui imn, „Acatistul Rugului Aprins”, a cărui strofă finală și refren este: „Bucură-te, Marie, maică a rugăciunii neîncetate". Vedem aici cum această experiență a rugăciunii coincide cu experiența Mariei în inima Bisericii”’31.

„Rugăciunea de foc” a Sfântului Ioan Casian se identifică cu rugăciunea isihastă și cu principiile Mișcării Rugului Aprins concretizare în Imnul Acatist despre care autorul, Sandu Tudor, afirmă: „Imnul acatist se arată și ca un cerc de foc și de flăcări al tuturor avânturilor noastre încordate...Fără îndoială, nimeni nu poate să primească și să înțeleagă,

${ }^{26}$ Carmen CiorneA, ,,Să nu fiți căldicei”. Sandu Tudor și întemeierea Rugului Aprins..., p. 55 .

27 Alexandru Mironescu, Floarea de foc, cuvânt înainte de Mihai Șora, postfață de Benedict Ghiuş, București, Edit. Eikon, 2019, p. 41-46.

${ }^{28}$ DANIIL DE La RARĂU - Sandu Tudor, Caiete 2. Sfințita Rugăciune, București, Edit. Christiana, 2009, p. 11.

${ }^{29}$ Ștefan Todirașcu, Comentarii la ,Poemele Filocalice” scrise de Alexandru Mironescu și alte eseuri, prefață de Horia Ion Groza, postfață de Pericle Martinescu, București, Edit. Eikon, 2017, p. 15.

${ }^{30}$ Sfântul Grigorie Palama, Scrieri II: Fecioara Maria și Petru Athonitul- prototipuri ale vieții isihaste și alte scrieri duhovnicești, studiu introductiv și traducere Ioan I. Ică jr, Sibiu, Edit. Deisis, 2005, p. 171-216, în special p. 207-208 și 212-213.

${ }^{31}$ Boris bobrinskoy, Compasiunea Tatălui, introducere de Maxim Egger, traducere din limba franceză de Nicolae Turcan, Cluj-Napoca, Edit. Renaşterea, 2017, p. 146. 
necum să încerce o bucurie, sorbind din acest fel de poezie, dacă nu a fost niciodată chinuit de foamea și setea contemplării" ${ }^{32}$.

\section{Concluzii}

Îndemnul Sfântului Apostol Pavel adresat tesalonicenilor: „Rugațivă neîncetat" (I Tesaloniceni 5, 17), precum și chemarea la sfințenie a tuturor oamenilor (Matei 5,48), modelul isihasmului laic exemplificat de Sfântul Nicolae Cabasila, de Sfầntul Voievod Neagoe Basarab și existent în mișcarea neoisihastă a secolului XVIII reprezentată pe teritoriul țării noastre de Sfântul Vasile de la Poiana Mărului și de Sfântul Paisie de la Neamt, reprezintă baza teologică a ,isihasmului laic".

Mai mult de atât, „Povestirile pelerinului rus” care arată evlavia mirenilor pentru „Rugăciunea lui Iisus”"33, exemplul autohton al „Moșului Gheorghe" din S,ugag (jud. Alba) ${ }^{34}$ canonizat în 25 martie 2018 sub numele de Sfântul Gheorghe Pelerinul (†1916), „o icoană vie a dreptei credinţe, un mărturisitor autentic al Ortodoxiei şi un exponent al valorilor ei sublime" după cum afirmă Înaltpreasfințitul Părinte Irineu ${ }^{35}$, și Mișcarea Rugului Aprins, reprezintă suficiente dovezi pentru existența unui ,isihasm laic”.

Pornind de la aceste mărturii considerăm a fi un lucru imperativ ca revigorarea duhovnicească a societății contemporane să înceapă de la „Rugăciunea lui Iisus”, bine știind că „rugăciunea inimii” nu este opțională ci ,este obligatorie pentru toți creștinii, în toată vremea și în tot locul"36.

32 Sandu Tudor, Seamă de cuvinte, apud Mihail Stanciu, „Părintele Daniil (Sandu Tudor), rugător și mărturisitor al Mântuitorului Iisus Hristos, partea a II-a- parcursul literar-duhovnicesc", în Ortodoxia, nr. 3/2013, p. 204.

${ }^{33}$ Ioan I. ICĂ JR, „Un epilog anonim al Filocaliei”, în Povestirile unui pelerin în căutarea rugăciunii neîncetate, Ed. a II-a, traducere și studiu introductiv diac. Ioan I. Ică jr., postfață Aleksei Pentkovski, Sibiu, Edit. Deisis, 2012, p. 13-14.

${ }^{34}$ Dumitru STĂNILOAE, Rugăciunea lui Iisus și experiența Duhului Sfânt, Ed. a II-a, cuvânt înainte de Gheorghios Grigoriatul, prefață de Olivier Clément, în românește de MariaCornelia Ică Jr., Sibiu, Edit. Deisis, 2003, p. 149-153.

35 †IRINEU, Arhiepiscop al Alba Iuliei, Sfântul Gheorghe Pelerinul revine în satul său natal, disponibil la: https://reintregirea.ro/mesaje-mass-media-la-diferite-ocazii/13556-sfantulgheorghe-pelerinul-revine-in-satul-sau-natal.html (accesat la 24.09.2019).

36 †IRINEU, Arhiepiscop al Alba Iuliei, „Cuvânt înainte”, în Rugăciunea lui Iisus în spiritualitatea ortodoxă, Alba Iulia, Edit. Reîntregirea, 2018, p. 6. 


\section{Referințe bibliografice:}

1. Alexandre, Monique, „La priere de feu chez Jean Cassien”, în Cristian Bădiliţă et Attila Jakab (ed.), Jean Cassien entre l"Orient et l"Occident. Actes du colloque internationel organise par le New Europe College en collaboration avec la Ludwing Boltzmann Gesellschaft (Bucarest, 27-28 septembre 2001), Paris, Beauchesne Editeur, Iași, Edit. Polirom, 2003, p. 169-203;

2. ANDRU, Vasile, Isihasmul sau meșteșugul liniștirii, București, Edit. Herald, 2010;

3. CionneA, Carmen, „Să nu fiți căldicei”. Sandu Tudor și întemeierea Rugului Aprins (1940-1952), prefaţă de Marius Oprea și cuvânt înainte de Nicolae Bordașiu, București, Edit. Eikon, 2018;

4. Sfântul GRIGORIE PALAMA, Scrieri II: Fecioara Maria și Petru Athonitulprototipuri ale vieții isihaste și alte scrieri duhovnicești, studiu introductiv şi traducere Ioan I. Ică jr, Sibiu, Edit. Deisis, 2005;

5. ICĂ jr., Ioan I., „Nicolae Cabasila - viața uitată a unui intelectual umanist isihast", în vol. Teologie ortodoxă în destin românesc: omagiu Părintelui Profesor Ilie Moldovan la 80 de ani, Sibiu, Edit. Andreiana, 2008, p. 363384 ;

6. Sfântul IOAN CASIAN, Convorbiri duhovnicești, traducere din limba latină de David Popescu, București, Edit. Institutului Biblic și de Misiune al Bisericii Ortodoxe Române, 2004;

7. †IRINEU, Arhiepiscop al Alba Iuliei, „Cuvânt înainte”, în Rugăciunea lui Iisus în spiritualitatea ortodoxă, Alba Iulia, Edit. Reîntregirea, 2018;

8. MeYENDORFF, John, O introducere în studiul vieții și operei Sfântului Grigorie Palama, traducere din limba franceză de Măriuca și Adrian Alexandrescu, studiu introductiv și traducere din limba greacă de Marius Portaru, București, Edit. Nemira, 2014;

9. PlămĂdeală, †Antonie, Rugul Aprins, Sibiu, Tipografia Eparhială Sibiu, 2002;

10. SCRIMA, André, Timpul rugului aprins: maestrul spiritual în tradiția răsăriteană, prefață de Andrei Pleșu, București, Edit. Humanitas, 2010;

11. STANCIU, Mihail, „Părintele Daniil (Sandu Tudor), rugător și mărturisitor al Mântuitorului Iisus Hristos, partea a II-a- parcursul literarduhovnicesc", în Ortodoxia, nr. 3/2013, p. 194-220; 
12. StĂNILOAE, Dumitru, Rugăciunea lui Iisus și experiența Duhului Sfânt, Ed. a II-a, cuvânt înainte de Gheorghios Grigoriatul, prefață de Olivier Clément, în românește de Maria-Cornelia Ică Jr., Sibiu, Edit. Deisis, 2003;

13. SuRdu, Alexandru, „'Isihasmul laic" la Neagoe Basarab”, în Omagiu Părintelui Academician Dumitru Popescu, Alba Iulia, Edit. Reîntregirea, 2005, p. 48-52. 